PROF. KIMBERLY MARTINOD (Orcid ID : 0000-0002-1026-6107)

Article type : Original Article

\title{
von Willebrand factor increases in experimental cerebral malaria but is not essential for late-stage pathogenesis in mice
}

Running head: von Willebrand factor in cerebral malaria

Sirima Kraisin*, Kimberly Martinod ${ }^{*, \dagger}$, Linda Desender*, Inge Pareyn*, Sebastien Verhenne*, Hans Deckmyn*, Karen Vanhoorelbeke*, Philippe E. Van den Steen $¥$, Simon F. De Meyer*

* Laboratory for Thrombosis Research, KU Leuven Campus Kulak Kortrijk, Kortrijk, Belgium

† Center for Molecular and Vascular Biology, Department of Cardiovascular Sciences, KU Leuven, Leuven, Belgium

‡ Laboratory of Immunoparasitology, Rega Institute for Medical Research, KU Leuven, Leuven, Belgium

\section{Correspondence:}

Simon F. De Meyer, Laboratory for Thrombosis Research

KU Leuven Campus Kulak Kortrijk

E. Sabbelaan 53

8500 Kortrijk

Belgium

tel: +3256246232

fax: +3256246997

Email: simon.demeyer@kuleuven.be

\section{Essentials}

This article has been accepted for publication and undergone full peer review but has not been through the copyediting, typesetting, pagination and proofreading process, which may lead to differences between this version and the Version of Record. Please cite this article as doi: $\underline{10.1111 / J T H .14932}$

This article is protected by copyright. All rights reserved 
- Clinical studies have suggested a link between von Willebrand factor (VWF) and malaria pathology.

- We studied the contribution of VWF in experimental cerebral malaria (ECM).

- VWF levels were increased during ECM.

- VWF deficiency did however not substantially influence the progression of ECM.

\section{Summary}

Background: Cerebral malaria $(\mathrm{CM})$ is the most severe complication in malaria. Endothelial activation, cytokine release and vascular obstruction are essential hallmarks of $\mathrm{CM}$. Clinical studies have suggested a link between von Willebrand factor (VWF) and malaria pathology.

Objectives: To investigate the contribution of VWF in the pathogenesis of experimental cerebral malaria (ECM).

Methods: Both $V_{w f} f^{+/}$and $V w f^{/-}$mice were infected with Plasmodium berghei ANKA (PbANKA) to induce ECM. Alterations of plasma VWF and ADAMTS13, platelet count, neurological features and accumulation of platelets and leukocytes in the brain were examined following infection.

Results: Plasma VWF levels significantly increased upon PbANKA infection in $\mathrm{Vwf}^{+/+}$animals. While ADAMTS13 activity was not affected, high molecular weight VWF multimers disappeared at the end-stage ECM, possibly due to an ongoing hypercoagulability. Although the number of reticulocytes, a preferential target for the parasites, was increased in $\mathrm{Vwf}^{/-}$mice compared to $\mathrm{Vwf}^{+/+}$mice early after infection, parasitemia levels did not markedly differ between the 2 groups. Interestingly, $V w f /$ mice manifested overall clinical ECM features similar to those observed in $\mathrm{Vwf}^{+/+}$animals. At day 8.5 post-infection, however, clinical ECM features in $V w f^{/-}$mice were slightly more beneficial than in $\mathrm{Vwf}^{+/+}$animals. Despite these minor differences, overall survival was not different between $\mathrm{Vwf}^{/-}$and $\mathrm{Vwf}^{+/+}$mice. Similarly, PbANKA-induced thrombocytopenia, leukocyte and platelet accumulations in the brains, were not altered by the absence of VWF.

Conclusions: Our study suggests that increased VWF concentration is a hallmark of ECM. However, VWF does not have a major influence in modulating late-stage ECM pathogenesis.

\section{Keywords}

Cerebral malaria, malaria, Plasmodium berghei ANKA, thrombocytopenia, von Willebrand factor

\section{Introduction}

Malaria is one of the most critical public health problems worldwide, leading to 219 million cases and 435,000 deaths in 2017.[1] Cerebral malaria (CM) is the most severe complication of Plasmodium falciparum infection and is responsible for most of the deaths.[1] The precise mechanisms underlying the pathophysiology of CM remain unclear, but previous studies have shown that sequestration of infected red blood cells (iRBCs) in the cerebral capillaries and postcapillary venules is a crucial factor in the disease 
pathology.[2-4] Parasite sequestration is mediated by the adhesion of iRBCs to activated endothelial cells (ECs). Several EC receptors such as CD36, intercellular adhesion molecule 1 (ICAM-1, P-selectin, and endothelial protein $C$ receptor (EPCR) were found to support iRBC adhesion.[5,6] In the brain, ICAM-1 and EPCR are probably the most important receptors in this respect.[7,8] Sequestration of iRBCs can result in vascular congestion, impaired perfusion, release of proinflammatory cytokines, local EC activation and the associated breakdown of the blood-brain barrier and subsequent cerebral edema. $[9,10]$

In addition to iRBC sequestration, leukocyte accumulation has also been observed in post-mortem brain sections from patients with CM.[11-13] In experimental CM (ECM), induced by $P$. berghei ANKA (PbANKA) infection in C57BL/6 mice, chemoattraction of activated perforin ${ }^{+} \mathrm{CD} 8^{+} \mathrm{T}$ cells to the brain is crucial for disease progression.[14,15] CD4+ $\mathrm{T}$ cells regulate $\mathrm{CD} 8^{+} \mathrm{T}$ cell recruitment, thereby modulating ECM pathogenesis.[16] Intravascular platelet accumulation has also been reported in patient post-mortem samples, a phenomenon that was more pronounced in patients with $\mathrm{CM}$ than in those with severe malarial anemia or nonmalarial encephalopathies.[12,17]

A potential role for von Willebrand factor (VWF) in the pathogenesis of severe malaria has previously been suggested.[18] VWF is a large multimeric glycoprotein synthetized in ECs and megakaryocytes. Following its synthesis, endothelial VWF is either constitutively secreted into plasma as a heterogenous series of multimers or stored in Weibel-Palade bodies (WPBs) as ultra-large (UL) VWF multimers. VWF plays a critical role in normal hemostasis by mediating platelet adhesion to exposed subendothelial structures at sites of vascular injury, and by protecting coagulation factor VIII from early degradation.[19] Furthermore, VWF is involved in inflammatory processes by recruiting leukocytes and promoting leukocyte extravasation either directly or indirectly via platelet GPIb.[20-22] The activity of VWF strictly correlates with the size of its multimers. VWF multimeric sizes are proteolytically regulated by ADAMTS13 (A Disintegrin And Metalloproteinase with a ThromboSpondin type 1 motif, member 13), an enzyme that cleaves VWF multimers into smaller sizes that are less active.

Clinical studies have shown that severe falciparum malaria is associated with increased levels of plasma VWF and decreased ADAMTS13 activity.[23-27] A number of studies have also reported an accumulation of ULVWF multimers that can spontaneously bind to platelets, which led to the hypothesis that the released ULVWF can contribute to thrombocytopenia in patients.[23,28-30] Most importantly, platelet-decorated VWF strings mediate $\mathrm{iRBC}$ binding to stimulated ECs in vitro, suggesting that VWF may facilitate iRBC sequestration and thus modulate disease progression.[31] Taken together, VWF is thought to contribute to severe malaria progression, but the exact mechanisms through which VWF potentially aggravates the disease are not fully investigated. In this study, we therefore used an established mouse model of ECM to investigate the role of VWF in the pathogenesis of ECM.

\section{Materials and Methods}

This article is protected by copyright. All rights reserved 


\section{Mice and parasite infection}

VWF knockout $\left(\mathrm{Vwf}^{-}\right)$) and wild-type $\left(\mathrm{Vwf}^{-}\right)$) were on a C57BL/6 background in-house generated from VWF heterozygous mice that were originally obtained from Jackson Laboratory (Bar Harbor, ME).

Characterization of $V w f /$ mice was previously described.[32] Both male and female mice were used in all experiments, with an age of 6 to 7 weeks at the time of infection. Different groups of mice in each experiment were age-, sex-, and weight-matched. To induce ECM, mice were intraperitoneally injected with $10^{4} \mathrm{RBC}$ infected with the PbANKA parasite ( $\mathrm{Cl} 15 \mathrm{cy} 1$, passage 4 after obtaining it as a kind gift from C. Janse, Leiden University Medical Center, The Netherlands) as previously described.[15] The drinking water of both infected and control mice was supplemented with $0.375 \mathrm{mg} / \mathrm{ml} \mathrm{p}$-aminobenzoic acid for optimal parasite growth.

Parasitemia levels were monitored by microscopy analysis of Giemsa-stained (1/10 dilution, Sigma-Aldrich, St. Louis, MO) thin blood smears. To make a thin blood smear, $2 \mu \mathrm{l}$ of blood collected by cutting approximately $1 \mathrm{~mm}$ of the tip of the mouse's tail was transferred to a microscope slide and spread by carefully pushing and sliding another clean slide along the length of the first slide. Gentle pressure was immediately applied on the tip of the tail until bleeding stopped. The percent parasitemia was determined by calculating the number of iRBCs in relation to the number of uninfected RBCs. A minimum of 800 total RBCs was counted per blood smear.

All mouse experiments were performed in accordance with protocols approved by the Institutional Animal Care and Use Committee of KU Leuven, Belgium. This study was approved under project number P173/2015.

\section{Severity assessment}

To assess disease progression, mice were evaluated according to the rapid murine coma and behavior scale (RMCBS) for quantitative assessment of murine cerebral malaria, as described [33] with minor modifications. Nine parameters were used to evaluate the animals, including gait, balance, motor performance, body position, limb strength, touch escape, pinna reflex, toe pinch and grooming. Each parameter was scored from 0 to 2 . Grooming, for example, ruffled hair, dusty hair/piloerection or with swaths of hair out of place, and normal/clean with sheen hair, were scored as 0,1 , and 2, respectively. Total cumulative minimum score of 0 (the lowest function) and a total cumulative maximum score of 18 (the highest function) were given. Following PbANKA infection, severity assessment was performed every 24 hours until 7 days post-infection (p.i.) and every 12 hours thereafter. Mice were euthanized when they reached a humane endpoint criterion of RMCBS scores of 4 or less, and this timepoint was defined as 'end stage'. Day of death was considered to be the following timepoint. Clinical assessment was done following the validated procedures [33] by the same operator in every experiment.

\section{Blood collection}

This article is protected by copyright. All rights reserved 
Unless stated otherwise, all blood samples were collected by retro-orbital puncture. Mice were anesthetized with $5 \%$ isoflurane (Nicholas Piramal Limited, London, UK) in $100 \% \mathrm{O}_{2}$. Blood samples treated with $0.5 \mathrm{M}$ ethylenediaminetetraacetic acid (1 volume to 40 volumes of blood) were used for platelet count measurements in whole blood. Platelet counts were measured using a Hemavet 950FS MultiSpecies Hematology system (Drew Scientific, Oxford, CT). For all measurements on plasma, blood was collected using $3.8 \%$ trisodium citrate ( 1 volume to 6 volumes of blood) as anticoagulant. Plasma was prepared from citrated blood by centrifugation at $4300 \times \mathrm{g}$ for 6 minutes and stored at $-80^{\circ} \mathrm{C}$ until analysis.

\section{VWF antigen determination}

VWF antigen (VWF:Ag) levels were determined in plasma by ELISA as described previously.[34] To compare the post-infection values with physiological baseline values in the same mice, the percentage of VWF:Ag in pre-infection samples was set as $100 \%$.

\section{Detection of VWF multimers}

VWF multimer patterns in plasma were determined as described previously.[35] In brief, mVWF was separated on sodium dodecyl sulfate $1.2 \%$ isoelectric focusing agarose gels. After gel fixation on Gelbond (Cambrex Bio Science Rockland, ME), mVWF was detected using anti-human VWF-IgG (Dako A0082) labeled with alkaline phosphatase (AP) and an AP conjugate substrate kit (Biorad, Hercules, CA). Multimer densitometry was performed using Image J software (version 1.49v, National Institutes of Health, Bethesda, $M D)$. For each multimer pattern, total number of distinguishable bands was counted and the relative abundance of low ( $1^{\text {st }}-5^{\text {th }}$ bands), medium ( $6^{\text {th }}-10^{\text {th }}$ bands), and high molecular weight (HMW) VWF multimers $\left(>10^{\text {th }}\right.$ band) was calculated as the relative value of the total area under the curve.

\section{Measurement of ADAMTS13 activity}

ADAMTS13 activity levels were determined in plasma using the fluorescent resonance energy transfer substrate VWF73 assay (Peptides International; Louisville, KY) as described previously.[36] To compare the post-infection values with physiological baselines in the same mice, the percentage of ADAMTS13 activity at baseline (pre-infection) was set as $100 \%$.

\section{Measurement of thrombin-antithrombin complexes and angiopoietin-2}

Mouse angiopoietin-2 (Ang-2) (Quantikine ELISA; R\&D Systems, MN) and thrombin-antithrombin (TAT) complexes (Abcam, Cambridge, UK) were measured by ELISA according to the manufacturer's instructions.

\section{Reticulocyte quantification}

Reticulocyte counts were determined via flow cytometry as described previously.[37] Briefly, $2 \mu$ of blood was collected by cutting approximately $1 \mathrm{~mm}$ of the tip of the mouse's tail and immersed immediately in 1 $\mathrm{ml}$ of $2 \%$ fetal calf serum (FCS) in Dulbecco's phosphate buffered saline. After counting the RBCs using a 
Bürker chamber (Thermo Fisher Scientific), approximately $2 \times 10^{6} \mathrm{RBCs}$ were taken from the solution for the quantification of reticulocytes. Cells were stained with APC/Cy7-conjugated anti-TER119 (Biolegend, San Diego, CA) and Brilliant Violet 421-conjugated anti-CD71 (Biolegend) antibodies. After washing steps, samples were analyzed using a BD FACSVerse flow cytometer (BD Biosciences, San Jose, CA) in conjunction with BD FACSuite Software. The percentage of reticulocytes (TER119+/CD71 hi) in the total RBC population (TER119+) was calculated using the gating strategy as shown in Fig S4.

\section{Flow cytometric analysis of leukocytes in the brain}

To isolate leukocytes from the brain, mice were deeply anesthetized and perfused transcardially with $30 \mathrm{ml}$ of ice-cold sterile phosphate-buffered saline (PBS). After perfusion, brains were removed and immediately cut along the sagittal plane. The right hemisphere was used for immunohistological detection of platelet accumulation, and the left hemisphere was used for flow cytometric detection of leukocyte subsets. For the latter, the brain tissue was mechanically homogenized and suspended in RPMI 1640 medium containing $2.5 \mathrm{mg} / \mathrm{ml}$ of collagenase type D (Thermo Fisher Scientific, Aalst, Belgium), $5 \mathrm{U} / \mathrm{ml}$ of DNase I (Thermo Fisher Scientific) and $10 \%$ of FCS. After incubation for 30 minutes at $37^{\circ} \mathrm{C}$, cell suspensions were passed through $70 \mu \mathrm{m}$ nylon cell strainers (Greiner Bio-One, Vilvoorde, Belgium) and centrifuged at $400 \times \mathrm{g}$ for 10 minutes. The pellet was then resuspended in $40 \%$ Percoll solution (GE Healthcare) and layered onto a $70 \%$ Percoll solution. After centrifugation, the cells (including leukocytes) at the interphase between the 2 Percoll layers were carefully collected, followed by washing and centrifugation steps. Cell pellets were resuspended in $100 \mu$ of PBS supplemented with $5 \%$ FCS. Next, the cell suspension was stained for 20 minutes with the following antibody mix (from Biolegend unless otherwise indicated): anti-mouse CD45APC, CD3ع-APC/Cy7, CD8a-PERCP/Cy5.5, CD4-FITC, and CD11b-PE/Cy7 (eBioscience). After washing steps, the cells were stained with Live/dead Fixable violet (Thermo Fisher Scientific) to exclude non-viable cells from the analysis. Singlets and live cells were identified, followed by gating CD45hi cells as leukocytes. Leukocyte subpopulations were then further differentiated according to specific surface markers. Finally, absolute values of total leukocytes were analyzed using BD FACSuite software and detailed analysis of leukocyte subsets was done with FlowJo software (FlowJo ${ }^{\text {TM }}$ ver.10; LLC, Ashland, OR).

\section{Immunohistochemical staining}

Perfused right hemisphere brain tissue was snap-frozen in optimal cutting temperature medium and cryosectioned at 9- $\mu \mathrm{m}$ thickness using a Leica CM 1950 cryostat (Leica Biosystems, Nussloch, Germany). Cryosections were stored at $-20^{\circ} \mathrm{C}$ prior to histological analysis. After fixation with ice-cold acetone, sections were incubated with Bloxall solution (Vector laboratories), followed by incubation with $5 \%$ rabbit serum (Dako). After washing steps, sections were incubated with purified rat anti-mouse GPIX antibody (1:200, Clone Xia.B4, Emfret) for 1 hour at room temperature (RT). After washing, a biotinylated secondary rabbit anti-rat IgG antibody (1:500, Vector Laboratories) in PBS buffer supplemented with $0.5 \%$ of rabbit serum and $0.1 \%$ of Tween 20 , was added for 30 minutes at RT. Bound secondary antibody was detected using the VECTASTAIN Elite ABC-HRP Kit (Vector Laboratories), followed by the VECTOR VIP peroxidase 
Substrate Kit (Vector Laboratories) according to the manufacturer's protocol. Methyl Green (Vector Laboratories) was used as a counterstain. After dehydration, slides were mounted with Sub-X Mounting Medium (Leica Biosystems) and visualized using a NanoZoomer-SQ digital slide scanner (Hamamatsu, Shizuoka, Japan). Isotype control stainings were performed by adding rat anti-mouse isotype lgG1 antibody (Biolegend), followed by incubation with secondary antibody and detection reagents as mentioned above. A group of GPIX-positive platelets with a total diameter of minimum $5 \mu \mathrm{m}$ was defined as a 'platelet cluster'. The number of platelet clusters in the whole hemisphere of each animal was quantified on 2 independent sections from different areas of the brain by an experimenter who was blinded for sample identity. Mean values were taken for analysis.

\section{Immunofluorescence staining}

Snap-frozen brain tissue was embedded in optimal-cutting temperature medium and cryosectioned at 9 $\mu \mathrm{m}$-thickness. Sections were fixed in ice-cold acetone for 15 minutes, dried, and rehydrated in PBS for 10 minutes. Blocking was performed with $5 \%$ normal rabbit serum and $3 \%$ bovine serum albumin in PBS for 1 hour at RT. Sections were incubated with a mixture of rat anti-GpIX (1:250, Clone Xia.B4, Emfret) and FITC-conjugated lectin from Lycopersicon esculentum (1:500 dilution, Sigma-Aldrich) for 2 hours at RT. After washing steps, sections were incubated with Alexa Fluor ${ }^{\mathrm{TM}}$ 555-conjugated goat anti-rat $\lg \mathrm{G}(\mathrm{H}+\mathrm{L})$ cross-adsorbed secondary antibody for 1 hour at RT. Slides were washed and sections were then counterstained for DNA using Hoechst 33342 (Invitrogen, 1:10000 dilution in water). Coverslips were mounted with SlowFade Diamond anti-fade mountant (Thermo Fisher Scientific). Images were acquired using an Axio-observer Z1 microscope (Zeiss) in conjunction with an Axiocam 506 monochromatic camera (Zeiss). Black and white individual channel images were pseudocolored and merged to generate color images with Zeiss Zen Blue software. Pictures taken with a Zeiss PlanApochromat 40X air objective, 0.95 NA, were used for microscopical analysis.

\section{Statistical analysis}

All statistical analyses were performed using Graphpad Prism software (Prism version 8.01 for Windows; La Jolla, CA). Log-Rank (Mantel-Cox) test was used to compare survival times between groups. Statistical differences between 2 groups were assessed using Mann-Whitney $U$ test or two-sample $t$-tests (2-tailed) based on the normal distribution test (D'Agostino-Pearson normality test). A paired $t$-test was used to compare the mean values from 2 related samples, i.e. before and after infection. To assess for significant differences between three or more independent groups, one-way ANOVA (parametric) or Kruskal-Wallis (non-parametric) analysis followed by a post-hoc test was applied. Continuous variables are expressed as mean values with standard deviation (SD) or as medians with interquartile range (IQR), as appropriate. A spearman correlation analysis was used to determine the association between RMCBS scores and number of platelet clusters in the brain. $P<0.05$ was considered statistically significant.

This article is protected by copyright. All rights reserved 


\section{Results}

\section{ECM is associated with increased VWF antigen levels and reduction of high molecular weight VWF multimers}

In order to study potential changes in VWF during the pathogenesis of ECM, we used an established mouse model of ECM, in which wild-type C57BL/6 mice were infected with PbANKA parasites (Fig S1).[15,38] Quantitative assessment of neurological signs was performed in 6 PbANKA-infected $V w f^{+/+}$ mice using the RMCBS scoring system.[33] Following infection, animals were monitored every 24 hours until day 7 p.i. and every 12 hours afterwards. RMCBS scores gradually decreased, indicating development of ECM features. An RMCBS score $\leq 4$ was typically reached at or after day 7.5 p.i., which was defined as 'end stage' (Fig S1). Next, we infected $7 \mathrm{Vwf}^{+/+}$mice with PbANKA parasites to follow the changes in VWF:Ag levels after infection. Subsets of these mice were used for measurements of Ang-2, ADAMTS13 activity, VWF multimers, and TAT complexes following the course of PbANKA infection (Fig 1). Blood samples were collected 2 weeks before infection, followed by 1, 3, 5, 7 days p.i., and at the end stage. VWF:Ag levels were significantly elevated in plasma collected at the end-stage of ECM compared with preinfection $(139.7 \pm 29.5 \%$ vs $100.1 \pm 7.2 \%$, respectively; $P<0.05)$ (Fig $1 \mathrm{~A})$. Such increases were not observed in PBS-injected controls (Fig S2A). Ang-2 is another glycoprotein stored in WPBs and secreted upon EC activation.[39] Similar to VWF:Ag, plasma Ang-2 levels were also significantly increased at day 7 p.i. $(79.4 \pm 17.3 \mathrm{ng} / \mathrm{ml})$ compared with baseline $(7.7 \pm 2.3 \mathrm{ng} / \mathrm{ml} ; P<0.001)$ (Fig 1B). Altogether, these data suggest that ECs are activated during the late stage in our ECM model. End-stage alterations were not seen for plasma ADAMTS13 activity. ADAMTS13 activity at the end stage of disease was comparable with pre-infection activity levels (Fig 1C).

Next, we analyzed VWF multimer composition in our ECM model. No circulating ULVWF multimers were present (Fig 1D). However, the amounts of HMW VWF multimers in the end-stage samples after PbANKA infection were significantly reduced compared with pre-infection levels $(34.8 \pm 6.9 \%$ vs $47.5 \pm 3.7 \%$, respectively; $P<0.05$ ) (Fig $1 \mathrm{E}$ ). Injection of PBS, on the other hand, did not change HMW VWF multimers (Fig S2B). Interestingly, TAT complexes at the end-stage disease $(17.6 \pm 2.2 \mathrm{ng} / \mathrm{ml})$ were significantly increased compared with baseline values $(7.1 \pm 0.7 \mathrm{ng} / \mathrm{ml} ; P<0.01)$ (Fig $1 \mathrm{~F})$, suggesting an ongoing hypercoagulability in the later stage, which might account for the consumption of HMW VWF multimers.

\section{VWF deficiency does not alter survival rates after PbANKA infection}

To investigate whether VWF is directly implicated in the pathogenesis of ECM, we studied PbANKA infection in $\mathrm{Vwf}^{/-}$mice in comparison with $\mathrm{Vwf}^{+/+}$controls. Seventeen $\mathrm{Vwf}^{+/+}$and sixteen $\mathrm{Vwf}^{\prime-}$ mice were infected with PbANKA. Parasitemia levels, clinical signs, and survival times of infected mice were monitored daily throughout the course of infection.

This article is protected by copyright. All rights reserved 
Following PbANKA infection, parasitemia levels gradually increased from 4 days p.i. onwards and reached approximately $15 \%$ at the end stage (Fig 2A). No significant differences in parasitemia levels were observed between $V w f^{/-}$and $V w f^{+/+}$mice, except on day 7.5 p.i., at which parasitemia levels in $V w f^{\prime-}$ mice were significantly higher than $V w f^{+/+}$animals $\left(18.8 \pm 10.9 \%\right.$ in $V w f^{/-}$mice vs $12.6 \pm 4.9 \%$ in $V w f^{+/+}$mice; $\left.P<0.05\right)$. In line with parasitemia levels, RMCBS scores between $V w f^{/-}$and $V w f^{+/+}$mice were overall not significantly different, except 8.5 days p.i., at which the mean RMCBS score (9.9) was higher for the remaining $V w f^{-}$mice $(7 / 16)$ than the mean score (3.8) of the remaining $V w f^{+/+}$mice $(8 / 17)(P<0.01)$ (Fig 2B). The average RMCBS scores from 9 days p.i. onwards are not shown in Fig $2 \mathrm{~B}$ because of the low number of remaining animals per group. The individual scores of all mice is presented in Fig S3.

Regardless of the small differences in parasitemia levels and clinical scores at the late stage, no significant difference in survival time between the 2 groups was observed $(P=0.39)$ (Fig $2 \mathrm{C}$ ).

Since $P$. berghei is known to have a predilection for invading reticulocytes (immature RBCs) over mature RBCs, [40-42], the number of circulating reticulocytes can be an important factor that moderates peripheral parasitemia levels. Therefore, we infected a new group of $\mathrm{Vwf}^{+/+}$and $\mathrm{Vwf}^{/-}$mice (8 mice/group) with $\mathrm{PbANKA}$ and quantified the reticulocyte numbers after infection via flow cytometry (Fig 2D and Fig S4). Reticulocyte numbers were significantly elevated in $\mathrm{Vwf}^{/-}$mice compared with $\mathrm{Vwf}^{+/+}$mice following PbANKA inoculation (Fig 2D). Notably, this increase was already seen at day 2 p.i. (5.4 $\pm 6.2 \%$ in $V w f^{/-}$ mice and $1.7 \pm 0.4 \%$ in $V w f^{+/+}$mice; $P<0.05$ ), which is prior to the appearance of parasites in the blood circulation. The elevated number of reticulocytes may account for the slightly increased parasitemia levels in $V w f /-m i c e$.

\section{Thrombocytopenia in ECM is VWF independent}

Thrombocytopenia is a common finding in patients with $P$. falciparum malaria.[43] By binding to platelets, VWF has been proposed to contribute to thrombocytopenia in patients with malaria.[30,44,45] In order to investigate whether VWF contributes to thrombocytopenia in ECM, we infected $5 \mathrm{Vwf}^{\mathrm{f} / \mathrm{H}}$ and $4 \mathrm{Vwf/-}$ mice and measured whole blood platelet counts at the end stage of PbANKA infection compared to baselines. In accordance with patient studies, severe thrombocytopenia was seen in our ECM model (Fig 3). Interestingly, however, the mean platelet count was similarly reduced in both PbANKA-infected $\mathrm{Vwf}^{+/+}$and $V w f^{/-}$mice. Indeed, platelet counts in $\mathrm{Vwf}^{+/+}$animals decreased from $703 \pm 102 \times 10^{3}$ platelets/ $\mu$ (baseline) to $92 \pm 27 \times 10^{3}$ platelets/ $\mu$ l (end stage, $P<0.001$ ) and from $734 \pm 73 \times 10^{3}$ platelets $/ \mu$ lo $99 \pm 58 \times 10^{3}$ platelets/ $\mu \mathrm{l}$ in $V w f^{/-}$mice $(P<0.01)$ (Fig 3). These data clearly demonstrate that thrombocytopenia in ECM model is VWF independent.

\section{ECM is associated with leukocyte accumulation in the brain through a VWF-independent mechanism}

This article is protected by copyright. All rights reserved 
Considering the fact that VWF is a known mediator of leukocyte recruitment,[20,21] we investigated the potential contribution of VWF on leukocyte accumulation in the brain during ECM. To this end, we infected $11 \mathrm{Vwf}^{+/+}$and $11 \mathrm{Vwf}^{/-}$mice. PBS-injected $\mathrm{Vwf}^{+/+}$(5 mice) and $\mathrm{Vwf}^{/-}(4 \mathrm{mice})$ animals were used as negative control. At 7.5 days p.i, perfused brains were isolated and cut along the sagittal plane. The left hemisphere was used to determine the number of infiltrating leukocytes via flow cytometry. The absolute number of total leukocytes (defined as $C D 45^{\text {hi }}$ cells), as well as the relative frequency of leukocyte subpopulations including myeloid cells (CD45 hi $C D 3-C D 11 b^{+}$cells), $C D 8^{+} T$ cells (CD45 ${ }^{\text {hi }} C D 3^{+} C D 8^{+}$cells), and $\mathrm{CD}^{+} \mathrm{T}$ cells $\left(\mathrm{CD} 45^{\mathrm{hi}} \mathrm{CD} 3^{+} \mathrm{CD} 4^{+}\right.$cells) were examined (the gating strategy is shown in Fig $\left.4 \mathrm{~A}\right)$. Leukocytes significantly accumulated in the brains of PbANKA-infected $V w f^{+/+}$mice $\left(139.9 \pm 70.7 \times 10^{3}\right.$ cells/hemisphere) (Fig 4B and $4 C$ ), whereas only a low number of leukocytes was detected in the brains of non-infected controls ( $7.4 \pm 1.4 \times 10^{3}$ cells/hemisphere) (Fig 4A and $4 \mathrm{C}$ ). Strikingly, leukocytes were also significantly recruited to the brain of PbANKA-infected $V w f^{\prime-}$ mice to a similar extent as was observed in $V w f^{\prime++}$ animals (125.5 $\pm 79.5 \times 10^{3}$ cells/hemisphere). Analysis of the relative frequency of leukocyte subpopulations revealed that $C D 8^{+} \mathrm{T}$ cells are the major population recruited in the brain during ECM $(55.2 \pm 12.6 \%$ of total leukocytes) (Fig 4C). Interestingly, similar patterns of leukocyte accumulation were observed in the brains of PbANKA-infected $\mathrm{Vwf}^{\prime}$ - mice (Fig $4 B$ and $4 C$ ). Also, no significant differences in the percentage of either myeloid cells, CD8 ${ }^{+} T$ cell, or $C D 4^{+} T$ cells were detected between $V w f^{+/+}$and $V w f^{/-}$mice (Fig 4C). Therefore, although leukocyte recruitment is a hallmark of ECM, it is not affected by VWF deficiency.

\section{ECM is associated with VWF-independent platelet aggregation in the cerebral vasculature}

Platelet accumulation occurs in the cerebral microvasculature of children with $\mathrm{CM}$ and is assumed to play a role in the pathogenesis of the disease.[11,12] Given the central role of VWF in platelet recruitment, we investigated the potential involvement of VWF in platelet accumulation during ECM.

While sagittal sections of the perfused left hemisphere were used to determine the leukocyte accumulation in the brain, the right hemispheres from the same animals were used to determine platelet aggregation in the brain. Platelets were visualized with an anti-mouse GPIX (CD42a) antibody. PBS-injected control mice did not show any signs of platelet accumulation in the brain (Fig 5A). In infected mice, on the other hand, platelet clusters were indeed detected (Fig $5 \mathrm{~A}$ ). Using immunofluorescent staining for platelets and delineation of endothelial cells with FITC-labeled tomato lectin, we found that those platelet clusters were located within the brain blood vessels (Fig 5B).

To determine whether the number of platelet aggregates in the brain was significantly different between $\mathrm{VWf}^{\mathrm{f} / \mathrm{+}}$ and $\mathrm{Vwf} /$ mice following PbANKA infection, we quantified the number of GPIX-positive platelet clusters in whole brain hemisphere sections. Interestingly, platelet aggregates were found in brain tissues from both $\mathrm{Vwf}^{+/+}$and $\mathrm{Vwf}^{/-}$mice infected with PbANKA. The number of platelet clusters were counted on two different sections and the mean from these two sections was taken as the representative value for the

This article is protected by copyright. All rights reserved 
animal. In $\mathrm{Vwf}^{+/+}$mice, this value ranged from 1.5 to 130 with a median of $9.5(\mathrm{IQR}=74)$ and whereas it ranged from 0.0 to 53.0 in $V w f^{/-}$mice (median $=2.5$; IQR =22) (Fig $5 \mathrm{C}$ ). No significant difference in platelet cluster numbers was seen between the 2 groups $(P=0.349)$ (Fig $5 C)$. Of note, the number of platelet clusters seen in the brains collected 7.5 days p.i. was inversely correlated with the RMCBS score monitored at the same day $(r=-0.6458, P<0.0012$, Fig 5D). Altogether, these data indicate that platelet accumulation in the cerebral vasculature observed in ECM is independent of VWF and correlates with disease severity.

\section{Discussion}

In this study, we investigated the possible contribution of VWF to ECM pathogenesis by using an established mouse model of ECM. After infection with PbANKA parasites, C57BL/6 mice develop neurological complications similar to those observed in patients with CM.[15] In accordance with clinical studies,[25-27,46] plasma VWF:Ag and Ang-2 levels increased during ECM, suggesting endothelial activation. Malarial parasite products such as glycosylphosphatidylinositol and hemozoin are able to induce the production of proinflammatory cytokines, which leads to EC damage and up-regulation of endothelial adhesion molecules.[47-49]. Interestingly, in a similar study of ECM by O'Regan et al., increased VWF levels were already observed at day 1 post-infection whereas VWF was only increased in a later stage of disease progression in our model.[50] In the study of O'Regan et al., this early increase was associated with the accumulation of ULVWF multimers in the circulation, a phenomenon also reported in patients with severe $P$. falciparum malaria,[23,28,29]. Possibly, the initial dose of iRBCs used to induce ECM may account for these differences between the two studies. The documented numbers of released merozoites from hepatic schizonts in the blood typically range from 2,000 to 30,000 in human malaria.[51] To mimic the human blood-stage condition, we infected our mice with $10^{4}$ iRBCs. In contrast, $2 \times 10^{6}$ iRBCs were used by O'Regan et al. to infect animals. Conceivably, this high dose was able to induce early and massive endothelial activation, leading to the appearance of ULVWF. In our study, the lower dose of iRBCs led to a slower progression of parasitemia and an increase of VWF and Ang-2 only at the late stage of PbANKA infection. No ULVWF was observed in our study. Possibly, ongoing hypercoagulability, as evidenced by increased levels of TAT complexes at late-stage infection, can lead to the consumption of HMW VWF at this stage of the disease. Interestingly, a similar loss of HMW VWF multimers was seen in our previous study of experimental MA-ARDS,[37] in which the loss of HMW VWF multimers occurred independently of the cleavage of VWF by ADAMTS13 or plasmin.[37]

In patients with severe malaria, a modest reduction in plasma ADAMTS13 activity has been reported.[23,24,28] We did not observe any reduction in plasma ADAMTS13 activity at the end stage of ECM, which is in agreement with O'Regan et al.[50] Interestingly, we have previously shown that $P$. berghei NK65-E (PbNK65) infection contributed to reduced ADAMTS13 activity possibly through the inhibition of ADAMTS13 activity. Hence, it seems likely that the alteration of ADAMTS13 activity in 
response to malaria infection might differ dependent on the parasite strains. While putative inhibitors of ADAMTS13 may be present upon PbNK65 infection, such inhibitors do not seem to appear during PbANKA infection in experimental malaria.

Thrombocytopenia is one of the most common complications in severe malaria.[43,52] VWF has been proposed to modulate thrombocytopenia in malaria by contributing to the enhanced platelet consumption. $[30,44,45]$ Our results indicate that thrombocytopenia in ECM is independent of VWF, which is in agreement with the findings of O'Regan et al.[50] Moreover, VWF-independent thrombocytopenia is also reported in experimental MA-ARDS.[37] Clearly, these data indicate that VWF is not responsible for malaria-associated thrombocytopenia. Other suggested mechanisms, including systemic platelet activation, immune-mediated clearance, formation of platelet-iRBCs complexes, and/or intravascular platelet accumulation,[53-56] may be responsible for thrombocytopenia.

In our model of ECM, there was no difference in clinical neurological symptoms between $\mathrm{Vwf}^{+/+}$and $V w f^{\prime}$, except at the very late-stage of PbANKA infection. Despite the latter, mortality rates were not significantly different between $\mathrm{Vwf}^{/}$-and $\mathrm{Vwf}^{+/+}$mice. These data suggest that, in our ECM model, VWF deficiency did not significantly affect the pathophysiology of ECM. Interestingly, our results differ from those reported by O'Regan et al., who observed that $V w f /$ mice developed delayed neurological signs of ECM and that VWF-deficient mice had slightly prolonged survival times compared with $\mathrm{Vwf}^{+/+}$controls.[50] As mentioned before, the different infection doses of iRBCs and the different time-points at which VWF is released may explain why VWF did significantly influence disease outcome in the study of O'Regan et al., but not in our study. Alternatively, differences in the clinical scoring system, which was used to define endpoints and thus survival times, could also lead to the difference seen in survival. The clinical score in our study was based on the RMCBS scoring system, which includes the assessment of body position, gait, fur condition, exploratory behavior, strength, reflexes and self-preservation.[33] In contrast, the algorithm used in the study of O'Regan did not include the latter 4 parameters. Instead, the appearance of limb paralysis, convulsions and coma were examined.[50,57]. Other factors that can possibly account for the observed differences between the 2 studies could include differences in parasite origin, substrain or parasite passages.

In line with clinical features and survival times, parasitemia levels were similar in both $\mathrm{Vwf}^{/-}$and $\mathrm{Vwf}^{+/+}$ mice. At the late stage of infection, however, parasitemia levels in $V w f^{-}$-mice appeared to be higher than in $\mathrm{VWf}^{+/+}$animals. This is possibly explained by the increases in circulating reticulocyte levels in $\mathrm{Vwf} /$ mice at the earlier time points, since $P$. berghei parasites prefer to invade reticulocytes over mature RBCs.[41,42,58] The observation regarding reticulocytosis in $V w f /$ mice is in agreement with our previous study in experimental MA-ARDS.[37] The biological mechanisms underlying this increased reticulocyte production in $V w f /$ mice following $P$. berghei infection at present remains unclear.

This article is protected by copyright. All rights reserved 
Immune effector cells have been proposed to be involved in the pathogenesis of CM.[11-13,59] Besides iRBCs, several studies have indeed reported that leukocytes also accumulated in the brain microvasculature of children with fatal CM.[11-13] In ECM, a number of studies have demonstrated that $\mathrm{CD}^{+} \mathrm{T}$ cells contribute to $\mathrm{ECM}$ progression potentially through their cytotoxic effector molecules, granzyme $B$ and perforin.[14,60-62] CD4+ $T$ cells have also been shown to contribute to the development of ECM by promoting $C D 8^{+} T$ cell accumulation. $[15,63]$ Our current study further corroborates the accumulation of leukocytes, predominantly CD8 ${ }^{+} \mathrm{T}$ cells, in the mouse brain during ECM. Interestingly, however, leukocyte recruitment was not mediated by VWF. Rapid release of endothelial P-selectin is impaired in Vwf/- mice, due to the absence of WPBs.[64] However, in our ECM model, a 10- to 100-fold increase in P-selectin mRNA was documented,[15] suggesting that de novo synthesis of P-selectin in the absence of VWF might be sufficient for leukocyte recruitment. Alternatively, other adhesion molecules, such as ICAM-1 and VCAM-1 might be important to recruit leukocytes, and consequently contribute to leukocyte accumulation in ECM.

Accumulation of platelets within brain microvessels of patients with CM has also been reported.[12,17] Grau et al. showed that platelets accumulated in the cerebral microvasculature of children with $\mathrm{CM}$ and colocalized with malaria pigment and leukocytes.[12] Similarly, platelet accumulation within the brain microvasculature has also been reported in ECM. $[65,66]$ Intravital imaging of the brain of mice with ECM revealed that small clusters of platelets were marginalized in post-capillary venules and co-localized with patches of P-selectin.[65] In line with these data, we also observed intravascular platelet accumulation in the brain in our model of ECM. Interestingly, such accumulation is largely independent of VWF and correlates with clinical severity. These data suggest that other platelet-binding molecules are probably involved, such as ICAM-1.[67]

Some limitations of this study should be taken into account. Although PbANKA infection in C57BL/6 mice is an established model of ECM, there are important differences with human CM.[68] For example, the substantial amount of iRBC sequestration, occluding brain microvasculature in a similar pattern to that observed in human CM, is less clear in ECM.[69] Given the fact that the potential ability of VWF in promoting $\mathrm{IRBC}$ adhesion was demonstrated in a human-liked in vitro condition,[31] interpretation and translation of our findings to human pathology should therefore be done with caution.

To conclude, elevated levels of plasma VWF are observed in both ECM and CM, and have been proposed to be involved in disease pathogenesis. Here, our data demonstrate that VWF does not play a major role in mediating brain leukocyte infiltration, intravascular platelet accumulation and overall disease progression and survival. More studies are needed to further elucidate the cause or consequence of increased VWF levels in malaria pathology.

\section{Addendum}

This article is protected by copyright. All rights reserved 
S. Kraisin and K. Martinod acquired, analyzed, and interpreted the data. S. Kraisin, and S. F. De Meyer wrote the manuscript. S. F. De Meyer supervised and designed the study. P. E. Van den Steen provided parasites, essential protocols, co-supervised the study and critically revised the manuscript. S. Verhenne guided and assisted with setting up the experiments. L. Desender and I. Pareyn performed experiments. H. Deckmyn revised the manuscript. K. Vanhoorelbeke co-supervised and revised the manuscript.

\section{Acknowledgements}

This study was supported by the Research Foundation-Flanders (FWO-Vlaanderen, project G086215N to P. E. Van den Steen and G070315 to S. F. De Meyer) and the Research Fund (C1 project C16/17/010 to P.E. Van den Steen) of the KU Leuven. K. Martinod was a H2020 Marie Skłodowska-Curie Actions fellow (under agreement number 747993, "VWF and NETs"). P. E. Van den Steen is a Research Professor at the $\mathrm{KU}$ Leuven. The funders had no role in study design, data collection and analysis, decision to publish, or preparation of the manuscript.

\section{Disclosure of Conflict of Interests}

The authors state that they have no conflict of interest.

\section{Supporting information}

Supporting Information can be found at the end of this manuscript.

\section{References}

1. World malaria report 2018. Geneva: World Health Organization.; 2018.

2. Ponsford MJ, Medana IM, Prapansilp P, Hien TT, Lee SJ, Dondorp AM, Esiri MM, Day NPJ, White NJ, Turner GDH. Sequestration and microvascular congestion are associated with coma in human cerebral malaria. J Infect Dis. 2012 Feb;205:663-71.

3. Maneerat Y, Pongponratn E, Viriyavejakul P, Punpoowong B, Looareesuwan S, Udomsangpetch R. Cytokines associated with pathology in the brain tissue of fatal malaria. Southeast Asian J Trop Med Public Health. 1999 Dec;30:643-9.

4. MacPherson GG, Warrell MJ, White NJ, Looareesuwan S, Warrell DA. Human cerebral malaria. A quantitative ultrastructural analysis of parasitized erythrocyte sequestration. Am J Pathol. 1985 Jun;119:385-401.

5. Ho M, White NJ. Molecular mechanisms of cytoadherence in malaria. Am J Physiol. 1999 Jun;276:C1231-42.

6. Turner L, Lavstsen T, Berger SS, Wang CW, Petersen JE V, Avril M, Brazier AJ, Freeth J, Jespersen JS, Nielsen MA, Magistrado P, Lusingu J, Smith JD, Higgins MK, Theander TG. Severe malaria is associated with parasite binding to endothelial protein C receptor. Nature. 2013 Jun;498:502-5.

This article is protected by copyright. All rights reserved 
7. Cooke B, Coppel R, Wahlgren M. Falciparum malaria: sticking up, standing out and out-standing. Parasitol Today. 2000 Oct; 16:416-20.

8. Moxon CA, Wassmer SC, Milner DAJ, Chisala N V, Taylor TE, Seydel KB, Molyneux ME, Faragher B, Esmon CT, Downey C, Toh C-H, Craig AG, Heyderman RS. Loss of endothelial protein C receptors links coagulation and inflammation to parasite sequestration in cerebral malaria in African children. Blood. 2013 Aug;122:842-51.

9. Mohanty S, Benjamin LA, Majhi M, Panda P, Kampondeni S, Sahu PK, Mohanty A, Mahanta KC, Pattnaik R, Mohanty RR, Joshi S, Mohanty A, Turnbull IW, Dondorp AM, Taylor TE, Wassmer SC. Magnetic Resonance Imaging of Cerebral Malaria Patients Reveals Distinct Pathogenetic Processes in Different Parts of the Brain. mSphere. 2017;2:e00193-17.

10. Seydel KB, Kampondeni SD, Valim C, Potchen MJ, Milner DA, Muwalo FW, Birbeck GL, Bradley WG, Fox LL, Glover SJ, Hammond CA, Heyderman RS, Chilingulo CA, Molyneux ME, Taylor TE. Brain swelling and death in children with cerebral malaria. N Engl J Med. 2015 Mar;372:1126-37.

11. Dorovini-zis K, Schmidt K, Huynh H, Fu W, Whitten RO, Milner D, Kamiza S, Molyneux M, Taylor TE. The Neuropathology of Fatal Cerebral Malaria in Malawian Children. Am J Pathol. 2011 May;178:2146-58.

12. Grau GE, Mackenzie CD, Carr RA, Redard M, Pizzolato G, Allasia C, Cataldo C, Taylor TE, Molyneux ME. Platelet Accumulation in Brain Microvessels in Fatal Pediatric Cerebral Malaria. J Infect Dis. 2003 Feb;187:461-6.

13. Patnaik JK, Das BS, Mishra SK, Mohanty S, Satpathy SK, Mohanty D. Vascular clogging, mononuclear cell margination, and enhanced vascular permeability in the pathogenesis of human cerebral malaria. Am J Trop Med Hyg. 1994 Nov;51:642-7.

14. Belnoue E, Kayibanda M, Vigario AM, Deschemin J-C, van Rooijen N, Viguier M, Snounou G, Renia L. On the pathogenic role of brain-sequestered alphabeta CD8+ T cells in experimental cerebral malaria. J Immunol. 2002 Dec;169:6369-75.

15. Van den Steen PE, Deroost K, Van Aelst I, Geurts N, Martens E, Struyf S, Nie CQ, Hansen DS, Matthys P, Van Damme J, Opdenakker G. CXCR3 determines strain susceptibility to murine cerebral malaria by mediating $\mathrm{T}$ lymphocyte migration toward IFN-gamma-induced chemokines. Eur J Immunol. 2008 Apr;38:1082-95.

16. Hermsen C, van de Wiel T, Mommers E, Sauerwein R, Eling W. Depletion of CD4+ or CD8+ T-cells prevents Plasmodium berghei induced cerebral malaria in end-stage disease. Parasitology. 1997 Jan;114:7-12.

17. Milner DAJ, Whitten RO, Kamiza S, Carr R, Liomba G, Dzamalala C, Seydel KB, Molyneux ME, Taylor TE. The systemic pathology of cerebral malaria in African children. Front Cell Infect Microbiol. 2014;4:104.

18. O'Sullivan JM, Preston RJS, O'Regan N, O'Donnell JS. Emerging roles for hemostatic dysfunction in malaria pathogenesis. Blood. 2016 May;127:2281-8.

19. Bryckaert M, Rosa J-P, Denis C V, Lenting PJ. Of von Willebrand factor and platelets. Cell Mol Life

This article is protected by copyright. All rights reserved 
Sci. 2015 Jan;72:307-26.

20. Petri BB, Broermann A, Li H, Khandoga AG, Zarbock A, Krombach F, Goerge T, Schneider SW, Jones C, Nieswandt B, Wild MK, Vestweber D. von Willebrand factor promotes leukocyte extravasation. Blood. 2010 Nov;116:4712-9.

21. Pendu R, Terraube V, Christophe OD, Gahmberg CG, de Groot PG, Lenting PJ, Denis C V. Pselectin glycoprotein ligand 1 and beta2-integrins cooperate in the adhesion of leukocytes to von Willebrand factor. Blood. 2006 Dec;108:3746-52.

22. Bernardo A, Ball C, Nolasco L, Choi H, Moake JL, Dong JF. Platelets adhered to endothelial cellbound ultra-large von Willebrand factor strings support leukocyte tethering and rolling under high shear stress. J Thromb Haemost. 2005 Mar;3:562-70.

23. de Mast Q, Groot E, Asih PB, Syafruddin D, Oosting M, Sebastian S, Ferwerda B, Netea MG, de Groot PG, van der Ven AJAM, Fijnheer R. ADAMTS13 deficiency with elevated levels of ultra-large and active von Willebrand factor in P. falciparum and P. vivax malaria. Am J Trop Med Hyg. 2009 Mar;80:492-8.

24. Lowenberg EC, Charunwatthana P, Cohen S, van den Born B-J, Meijers JCM, Yunus EB, Hassan MU, Hoque G, Maude RJ, Nuchsongsin F, Levi M, Dondorp AM. Severe malaria is associated with a deficiency of von Willebrand factor cleaving protease, ADAMTS13. Thromb Haemost. 2010 Jan;103:181-7.

25. Phiri HT, Bridges DJ, Glover SJ, van Mourik JA, de Laat B, M'baya B, Taylor TE, Seydel KB, Molyneux ME, Faragher EB, Craig AG, Bunn JEG. Elevated plasma von Willebrand factor and propeptide levels in Malawian children with malaria. PLoS One. 2011;6:e25626.

26. Conroy AL, Phiri H, Hawkes M, Glover S, Mallewa M, Seydel KB, Taylor TE, Molyneux ME, Kain $\mathrm{KC}$. Endothelium-based biomarkers are associated with cerebral malaria in Malawian children: a retrospective case-control study. PLoS One. 2010 Dec;5:e15291.

27. Hollestelle MJ, Donkor C, Mantey EA, Chakravorty SJ, Craig A, Akoto AO, O'Donnell J, van Mourik JA, Bunn J. von Willebrand factor propeptide in malaria: evidence of acute endothelial cell activation. Br J Haematol. 2006 Jun;133:562-9.

28. Larkin D, de Laat B, Jenkins PV, Bunn J, Craig AG, Terraube V, Preston RJS, Donkor C, Grau GE, van Mourik JA, O'Donnell JS. Severe Plasmodium falciparum malaria is associated with circulating ultra-large von Willebrand multimers and ADAMTS13 inhibition. PLoS Pathog. 2009 Mar;5:e1000349.

29. Graham SM, Chen J, Chung DW, Barker KR, Conroy AL, Hawkes MT, Namasopo S, Kain KC, Lopez JA, Liles WC. Endothelial activation, haemostasis and thrombosis biomarkers in Ugandan children with severe malaria participating in a clinical trial. Malar J. 2016 Feb;15:56.

30. de Mast Q, de Groot PG, van Heerde WL, Roestenberg M, van Velzen JF, Verbruggen B, Roest M, McCall M, Nieman A-E, Westendorp J, Syafruddin D, Fijnheer R, van Dongen-Lases EC, Sauerwein $\mathrm{RW}$, van der Ven AJ. Thrombocytopenia in early malaria is associated with GP1b shedding in absence of systemic platelet activation and consumptive coagulopathy. $\mathrm{Br} \mathrm{J}$ Haematol. 2010

This article is protected by copyright. All rights reserved 
Dec;151:495-503.

31. Bridges DJ, Bunn J, van Mourik JA, Grau G, Preston RJS, Molyneux M, Combes V, O'Donnell JS, de Laat B, Craig A. Rapid activation of endothelial cells enables Plasmodium falciparum adhesion to platelet-decorated von Willebrand factor strings. Blood. 2010 Feb;115:1472-4.

32. Denis C, Methia N, Frenette PS, Rayburn H, Ullman-Cullere M, Hynes RO, Wagner DD. A mouse model of severe von Willebrand disease: defects in hemostasis and thrombosis. Proc Natl Acad Sci U S A. 1998 Aug;95:9524-9.

33. Carroll RW, Wainwright MS, Kim K-Y, Kidambi T, Gomez ND, Taylor T, Haldar K. A rapid murine coma and behavior scale for quantitative assessment of murine cerebral malaria. PLoS One. 2010 Oct; $5: e 13124$.

34. Verhenne S, Denorme F, Libbrecht S, Vandenbulcke A, Pareyn I, Deckmyn H, Lambrecht A, Nieswandt B, Kleinschnitz C, Vanhoorelbeke K, De Meyer SF. Platelet-derived VWF is not essential for normal thrombosis and hemostasis but fosters ischemic stroke injury in mice. Blood. 2015 Oct;126:1715-22.

35. De Meyer SF, Vandeputte N, Pareyn I, Petrus I, Lenting PJ, Chuah MKL, VandenDriessche T, Deckmyn $\mathrm{H}$, Vanhoorelbeke K. Restoration of plasma von Willebrand factor deficiency is sufficient to correct thrombus formation after gene therapy for severe von Willebrand disease. Arterioscler Thromb Vasc Biol. 2008 Sep;28:1621-6.

36. De Cock E, Hermans C, De Raeymaecker J, De Ceunynck K, De Maeyer B, Vandeputte N, Vandenbulcke A, Deckmyn H, Rottensteiner H, De Maeyer M, De Meyer SF, Vanhoorelbeke K. The novel ADAMTS13-p.D187H mutation impairs ADAMTS13 activity and secretion and contributes to thrombotic thrombocytopenic purpura in mice. J Thromb Haemost. 2015 Feb;13:283-92.

37. Kraisin S, Verhenne S, Pham T-T, Martinod K, Tersteeg C, Vandeputte N, Deckmyn H, Vanhoorelbeke K, Van den Steen PE, De Meyer SF. von Willebrand factor in experimental malariaassociated acute respiratory distress syndrome. J Thromb Haemost. 2019 May;17:1372-83.

38. de Souza JB, Riley EM. Cerebral malaria: the contribution of studies in animal models to our understanding of immunopathogenesis. Microbes Infect. 2002 Mar;4:291-300.

39. Fiedler U, Scharpfenecker M, Koidl S, Hegen A, Grunow V, Schmidt JM, Kriz W, Thurston G, Augustin HG. The Tie-2 ligand angiopoietin-2 is stored in and rapidly released upon stimulation from endothelial cell Weibel-Palade bodies. Blood. 2004 Jun;103:4150-6.

40. Vandermosten L, Pham T-T, Possemiers H, Knoops S, Van Herck E, Deckers J, Franke-Fayard B, Lamb TJ, Janse CJ, Opdenakker G, Van den Steen PE. Experimental malaria-associated acute respiratory distress syndrome is dependent on the parasite-host combination and coincides with normocyte invasion. Malar J. 2018 Mar;17:102.

41. Deharo E, Coquelin F, Chabaud AG, Landau I. The erythrocytic schizogony of two synchronized strains of plasmodium berghei, NK65 and ANKA, in normocytes and reticulocytes. Parasitol Res. 1996;82:178-82.

42. Cromer D, Evans KJ, Schofield L, Davenport MP. Preferential invasion of reticulocytes during late-

This article is protected by copyright. All rights reserved 
stage Plasmodium berghei infection accounts for reduced circulating reticulocyte levels. Int $\mathrm{J}$ Parasitol. 2006 Nov;36:1389-97.

43. Cox D, McConkey S. The role of platelets in the pathogenesis of cerebral malaria. Cell Mol Life Sci. 2010 Feb;67:557-68.

44. de Mast Q, Groot E, Lenting PJ, de Groot PG, McCall M, Sauerwein RW, Fijnheer R, van der Ven A. Thrombocytopenia and release of activated von Willebrand Factor during early Plasmodium falciparum malaria. J Infect Dis. 2007 Aug;196:622-8.

45. Schwameis M, Schorgenhofer C, Assinger A, Steiner MM, Jilma B. VWF excess and ADAMTS13 deficiency: a unifying pathomechanism linking inflammation to thrombosis in DIC, malaria, and TTP. Thromb Haemost. 2015 Apr;113:708-18.

46. Lovegrove FE, Tangpukdee N, Opoka RO, Lafferty El, Rajwans N, Hawkes M, Krudsood S, Looareesuwan S, John CC, Liles WC, Kain KC. Serum angiopoietin-1 and -2 levels discriminate cerebral malaria from uncomplicated malaria and predict clinical outcome in African children. PLoS One. 2009;4:e4912.

47. Vijaykumar M, Naik RS, Gowda DC. Plasmodium falciparum glycosylphosphatidylinositol-induced TNF-alpha secretion by macrophages is mediated without membrane insertion or endocytosis. $\mathrm{J}$ Biol Chem. 2001 Mar;276:6909-12.

48. Schofield L, Novakovic S, Gerold P, Schwarz RT, Mcconville MJ, Tachado SD. Glycosylphosphatidylinositol toxin of Plasmodium up-regulates intercellular adhesion molecule-1, vascular cell adhesion molecule-1, and E-selectin expression in vascular endothelial cells and increases leukocyte and parasite cytoadherence via tyrosine kin. J Immunol. 1996;156:1886-96.

49. Schofield L, Grau GE. Immunological processes in malaria pathogenesis. Nat Rev Immunol. 2005;5:722-35.

50. O'Regan N, Gegenbauer K, O'Sullivan JM, Maleki S, Brophy TM, Dalton N, Chion A, Fallon PG, Grau GE, Budde U, Smith OP, Craig AG, Preston RJS, O'Donnell JS. A novel role for von Willebrand factor in the pathogenesis of experimental cerebral malaria. Blood. 2016 Mar;127:1192201.

51. White NJ. Malaria. In: Cook GC, Zumla A, Manson P, editors. Manson's Tropical Diseases. 22nd ed. Edinburgh: Saunders Ltd.; 2009.

52. Faille D, El-Assaad F, Alessi M-C, Fusai T, Combes V, Grau GE. Platelet-endothelial cell interactions in cerebral malaria: the end of a cordial understanding. Thromb Haemost. 2009 Dec;102:1093-102.

53. Lacerda MVG, Mourao MPG, Coelho HCC, Santos JB. Thrombocytopenia in malaria: who cares? Mem Inst Oswaldo Cruz. 2011 Aug;106 Suppl:52-63.

54. Coelho HCC, Lopes SCP, Pimentel JPD, Nogueira PA, Costa FTM, Siqueira AM, Melo GC, Monteiro WM, Malheiro A, Lacerda MVG. Thrombocytopenia in Plasmodium vivax malaria is related to platelets phagocytosis. PLoS One. 2013;8:e63410.

55. Kelton JG, Keystone J, Moore J, Denomme G, Tozman E, Glynn M, Neame PB, Gauldie J, Jensen 
J. Immune-mediated thrombocytopenia of malaria. J Clin Invest. 1983 Apr;71:832-6.

56. Kho S, Barber BE, Johar E, Andries B, Poespoprodjo JR, Kenangalem E, Piera KA, Ehmann A, Price RN, William T, Woodberry T, Foote S, Minigo G, Yeo TW, Grigg MJ, Anstey NM, McMorran BJ. Platelets kill circulating parasites of all major Plasmodium species in human malaria. Blood. 2018 Sep;132:1332-44.

57. Amante FH, Stanley AC, Randall LM, Zhou Y, Haque A, McSweeney K, Waters AP, Janse CJ, Good MF, Hill GR, Engwerda CR. A role for natural regulatory $T$ cells in the pathogenesis of experimental cerebral malaria. Am J Pathol. 2007 Aug;171:548-59.

58. Butcher GA, Mitchell GH, Cohen S. Letter: Mechanism of host specificity in malarial infection. Nature. 1973 Jul;244:40-1.

59. Hochman SE, Madaline TF, Wassmer SC, Mbale E, Choi N, Seydel KB, Whitten RO, Varughese J, Grau GER, Kamiza S, Molyneux ME, Taylor TE, Lee S, Milner DAJ, Kim K. Fatal Pediatric Cerebral Malaria Is Associated with Intravascular Monocytes and Platelets That Are Increased with HIV Coinfection. MBio. 2015 Sep;6:e01390-15.

60. Swanson PA 2nd, Hart GT, Russo M V, Nayak D, Yazew T, Pena M, Khan SM, Janse CJ, Pierce SK, McGavern DB. CD8+ T Cells Induce Fatal Brainstem Pathology during Cerebral Malaria via Luminal Antigen-Specific Engagement of Brain Vasculature. PLoS Pathog. 2016 Dec;12:e1006022.

61. Nitcheu J, Bonduelle O, Combadiere C, Tefit M, Seilhean D, Mazier D, Combadiere B. Perforindependent brain-infiltrating cytotoxic $\mathrm{CD} 8+\mathrm{T}$ lymphocytes mediate experimental cerebral malaria pathogenesis. J Immunol. 2003 Feb;170:2221-8.

62. Haque A, Best SE, Unosson K, Amante FH, de Labastida F, Anstey NM, Karupiah G, Smyth MJ, Heath WR, Engwerda CR. Granzyme B expression by CD8+ T cells is required for the development of experimental cerebral malaria. J Immunol. 2011 Jun;186:6148-56.

63. Campanella GS V, Tager AM, El Khoury JK, Thomas SY, Abrazinski TA, Manice LA, Colvin RA, Luster AD. Chemokine receptor CXCR3 and its ligands CXCL9 and CXCL10 are required for the development of murine cerebral malaria. Proc Natl Acad Sci U S A. 2008 Mar;105:4814-9.

64. Denis C V, Andre P, Saffaripour S, Wagner DD. Defect in regulated secretion of P-selectin affects leukocyte recruitment in von Willebrand factor-deficient mice. Proc Natl Acad Sci U S A. 2001 Mar;98:4072-7.

65. Nacer A, Movila A, Sohet F, Girgis NM, Gundra UM, Loke P, Daneman R, Frevert U. Experimental cerebral malaria pathogenesis--hemodynamics at the blood brain barrier. PLoS Pathog. 2014 Dec;10:e1004528.

66. Nacer A, Movila A, Baer K, Mikolajczak SA, Kappe SHI, Frevert U. Neuroimmunological blood brain barrier opening in experimental cerebral malaria. PLoS Pathog. 2012;8:e1002982.

67. Sun G, Chang W-L, Li J, Berney SM, Kimpel D, van der Heyde HC. Inhibition of platelet adherence to brain microvasculature protects against severe Plasmodium berghei malaria. Infect Immun. 2003 Nov;71:6553-61.

68. Ghazanfari N, Mueller SN, Heath WR. Cerebral Malaria in Mouse and Man. Front Immunol.

This article is protected by copyright. All rights reserved 
2018;9:1-11.

69. Franke-Fayard B, Janse CJ, Cunha-Rodrigues M, Ramesar J, Buscher P, Que I, Lowik C, Voshol PJ, den Boer MAM, van Duinen SG, Febbraio M, Mota MM, Waters AP. Murine malaria parasite sequestration: $\mathrm{CD} 36$ is the major receptor, but cerebral pathology is unlinked to sequestration. Proc Natl Acad Sci U S A. 2005 Aug;102:11468-73.

\section{Figure legends}

Figure 1. Changes in plasma values for VWF, Ang-2, ADAMTS13 activity and TAT complexes during ECM.

Seven C57BL/6 $\left(V f^{+/+}\right)$mice were infected with $10^{4} \mathrm{PbANKA}$ parasites. Plasma samples were collected 2 weeks before infection (Pre), at indicated days p.i., and at the end stage of disease i.e. when RMCBS score $\leq 4$ (End). One animal died at day 7 before plasma was collected. All plasma samples were used to measure VWF:Ag. Samples of the 6 animals with plasma collected until the end stage were used to measure Ang-2 levels and ADAMT13 activity. For Ang-2 (determined during revisions), one End-stage sample did not contain sufficient plasma. Samples from four and five animals (randomly chosen) were used to measure VWF multimers and TAT complexes respectively. (A) Plasma VWF:Ag levels measured by ELISA are shown as percentage of pre-values, which were set as $100 \%$. (B) Plasma Ang2 levels were measured by ELISA. (C) Plasma ADAMTS13 activity levels were assessed using FRET-VWF73 assay. Pre-infection activity levels were set as $100 \%$. (D) VWF multimer compositions were determined by agarose gel electrophoresis and densitometry. Representative VWF multimer distributions of one PbANKA-infected mouse is shown. (E) VWF multimer compositions were analyzed using densitometry. Relative abundance of HMW VWF multimers is shown. (F) Levels of plasma TAT complexes were measured by ELISA. Results represent the mean

This article is protected by copyright. All rights reserved 
values \pm standard deviation $\left({ }^{*} P<0.05,{ }^{* *} P<0.001\right.$; NS, Not significant). LMW, low molecular weight $\left(1^{\text {st }}-5^{\text {th }}\right.$ bands); MMW, medium molecular weight $\left(6^{\text {th }}-10^{\text {th }}\right.$ bands); HMW, high molecular weight $\left(>10^{\text {th }}\right.$ bands).

Figure 2. Parasitemia, clinical scores and survival rates after PbANKA infection. $V w f^{+/+}(n=17)$ and $V w f^{/-}(n=16)$ mice were infected with $10^{4} \mathrm{PbANKA}$-infected red blood cells. Day of infection was considered as day 0 post-infection. (A) Peripheral parasitemia levels were determined from Giemsa-stained blood smears. (B) Clinical features and ECM progression were assessed using the RMCBS scoring system. Individual scoring curves are shown in Figure S3. (C) Overall survival of the infected mice was determined and analyzed by log-rank (Mantel-Cox) test. (D) To quantify the reticulocyte numbers, a separate group of $\mathrm{Vwf}^{+/+}$and $\mathrm{Vwf} /$ - mice ( $\mathrm{n}=8$ per group) were infected with $10^{4} \mathrm{PbANKA}-$ infected red blood cells. Percentage of reticulocytes (TER119+CD71 hi) in the total number of erythrocytes (TER119+) was measured by flow cytometry. Results represent the mean values \pm standard deviation $\left({ }^{*} P<0.05\right.$ and $\left.{ }^{* *} P<0.01\right)$. Solid lines and dash lines represent data from $\mathrm{Vwf}^{+/+}$and $\mathrm{Vwf/-}$ mice, respectively.

Figure 3. VWF does not mediate thrombocytopenia in end-stage ECM. $V w f^{+/+}(n=5)$ and $V w f^{/-}(n=4)$ mice were infected with $10^{4}$ PbANKA-infected red blood cells. Blood samples were taken 2 weeks before the infection (Pre) and at the end stage of disease when RMCBS score $\leq 4$ (End). Platelet counts were measured using an automated cell counter. Results represent the mean values \pm standard deviation $\left({ }^{* *} P<0.01 ;{ }^{* *} P<0.001\right)$. Closed and open circles represent data from $V w f^{+/+}$and $V w f^{/-}$mice, respectively.

Figure 4. Increased leukocyte recruitment into the brain of ECM is independent of VWF. $V w f^{+/+}$and $V w f^{/-}$mice were infected with $10^{4}$ PbANKA-infected red blood cells ( $n=11$ per group) or PBS ( $\mathrm{n}=5$ for $V w f^{+/+}$and $n=4$ for $V w f^{/ /}$). Number of leukocytes in the left hemisphere of the perfused brains harvested 7.5 days p.i. were determined using flow cytometry. (A) Representative flow cytometry data showing gating strategy. Leukocytes (defined as CD45i cells) were further differentiated as myeloid cells (CD45 hi CD11 $b^{+}$cells), T cells (CD45 hiCD3 ${ }^{+}$cells), CD8 ${ }^{+} T$ cells

$\left(C D 45^{\text {hi }} \mathrm{CD} 3^{+} \mathrm{CD} 8^{+}\right.$cells), and $C D 4^{+} T$ cells $\left(C D 45^{\text {hi }} C D 3^{+} C D 4^{+}\right.$cells). (B) Representative flow cytometry data showing leukocyte populations in $\mathrm{Vwf}^{+/+}$and $\mathrm{Vwf} /$-mice following PbANKA infection. (C) Absolute leukocyte number per brain hemisphere is present on the left panel. Relative distribution of leukocyte subpopulations, i.e. myeloid cells, CD8 ${ }^{+} \mathrm{T}$ cells, CD4 ${ }^{+} \mathrm{T}$ cells, and other leukocyte subpopulations, are shown on the right panel. Results represent the mean values \pm standard deviation ( ${ }^{*} P<0.05 ;{ }^{* *} P<0.01$; NS, not significant).

Figure 5. Platelet accumulation within the cerebral microvasculature of mice with ECM. (A) The right hemispheres of the same animals described in Figure 4 were used. Brain sections were stained for GPIX to identify platelets (dense purple staining), and counterstained with methyl green. Representative images are shown (scale bar, $10 \mu \mathrm{m}$ ). (B) Representative images showing immunofluorescent staining of brain sections. Tomato lectin (green, vascular endothelium), platelets (red), and DNA (blue) are shown (scale bar, $10 \mu \mathrm{m}$ ). (C) The number of GPIX-positive platelet clusters in 2 independent brain sections per animal were counted from immunohistochemically stained tissues. Box plots show the median values and describe the data variability. Kruskal-Wallis test followed by Dunn's multiple comparisons was applied to determine the differences in number of platelet clusters. No statistical differences were observed between PbANKA-infected $\mathrm{Vwf}^{+/+}$and $\mathrm{Vwf}^{/-}$mice. (D) A Spearman correlation analysis performed to determine the degrees of correlation between the RMBCS scores and the number of platelet clusters in the brain.

This article is protected by copyright. All rights reserved 
A

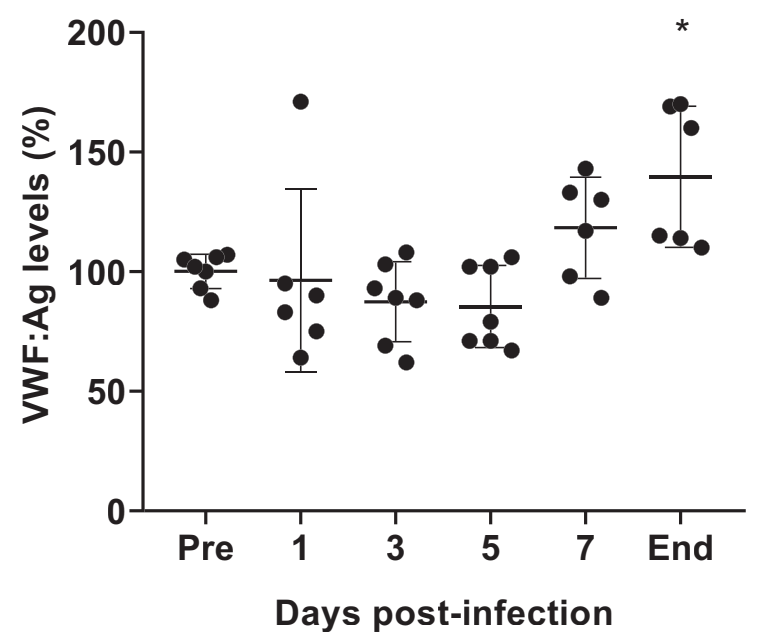

C

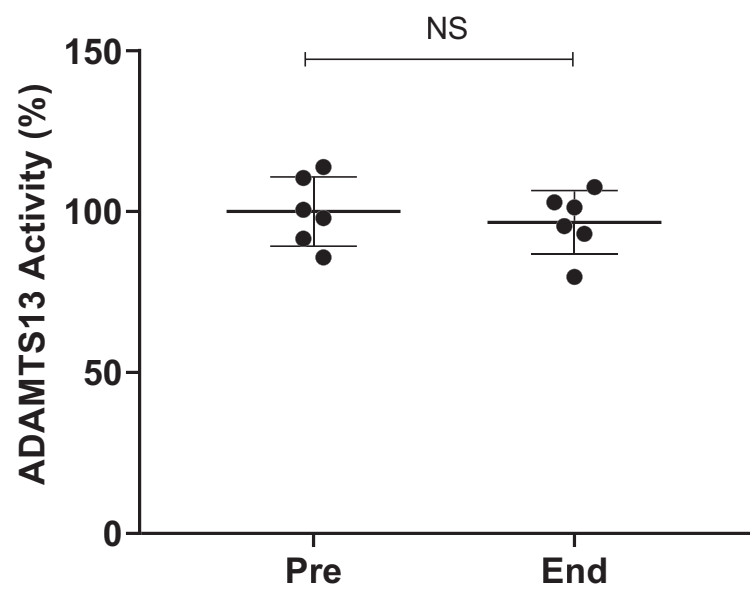

E

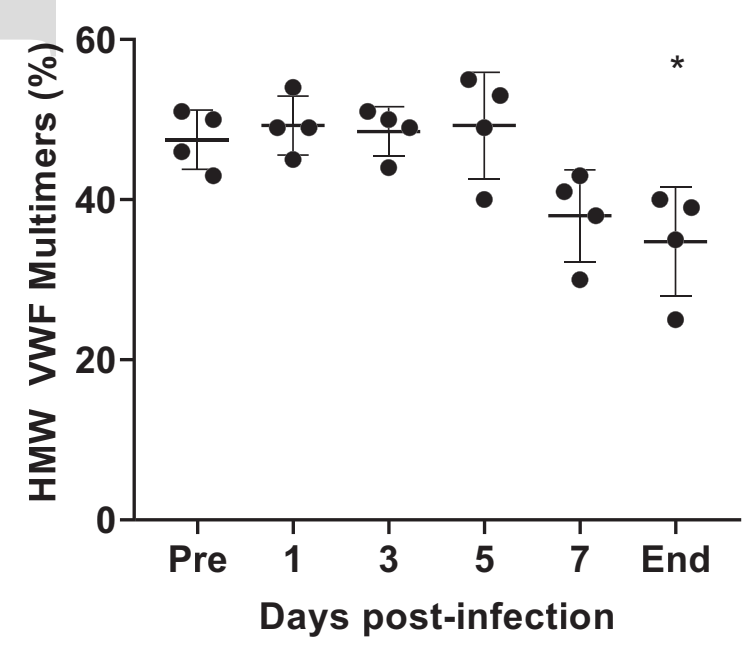

B

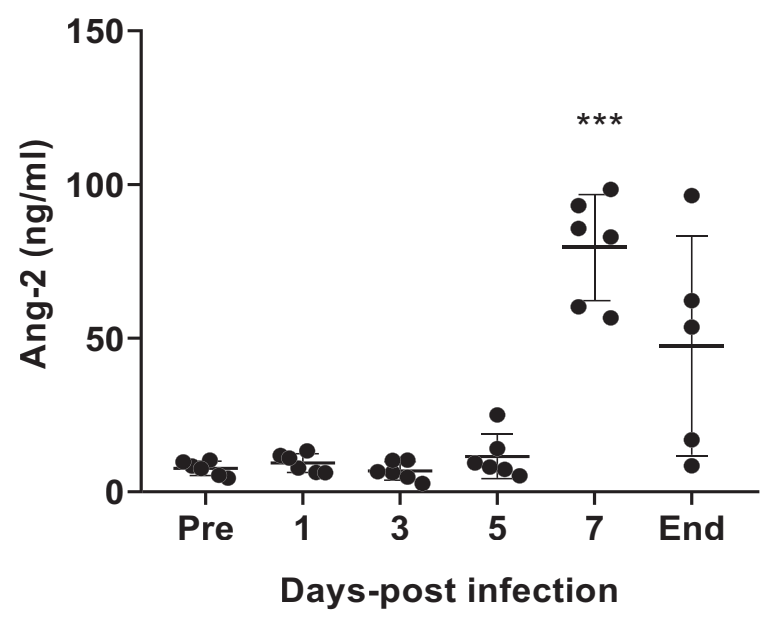

D

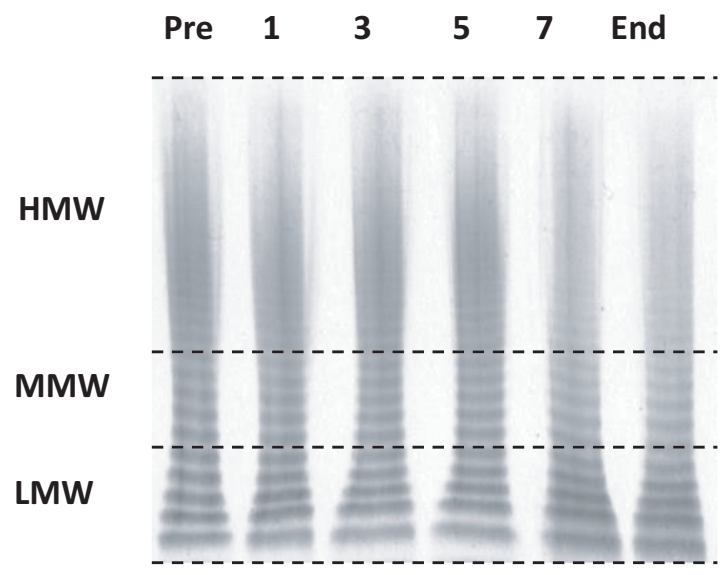

$\mathbf{F}$

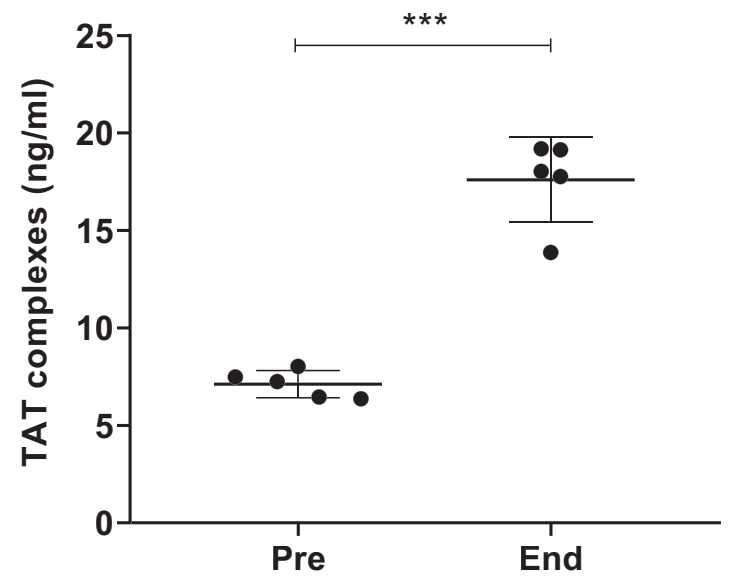

This article is protected by copyright. All rights reserved 
A

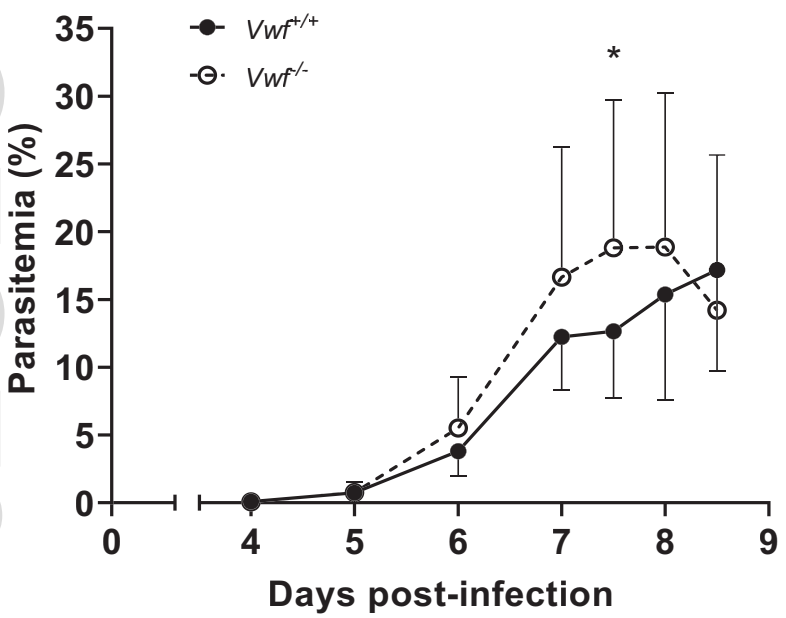

C

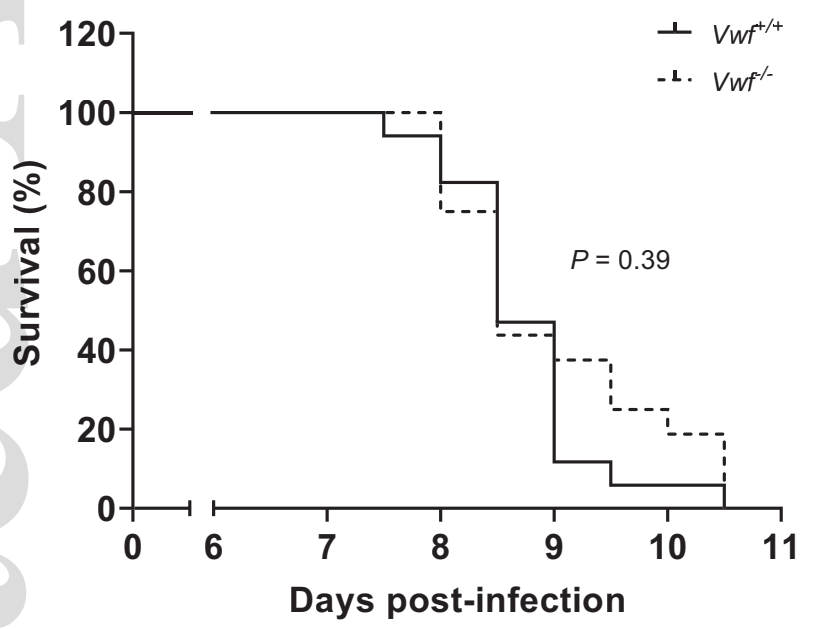

B

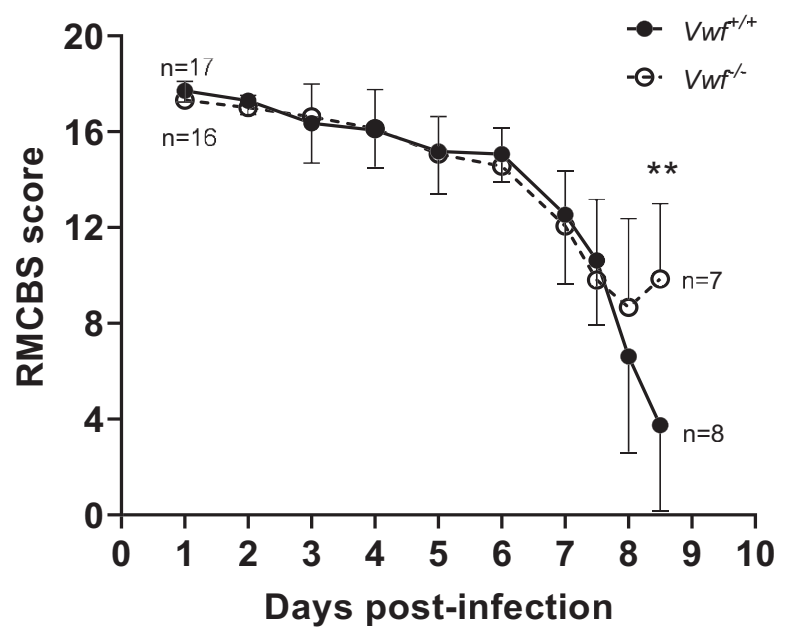

D

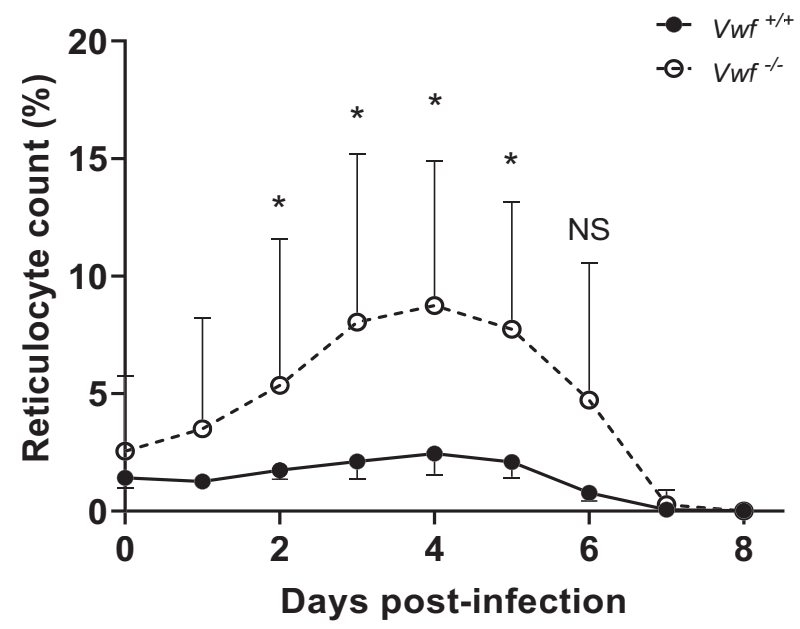

jth_14932_f2.eps

This article is protected by copyright. All rights reserved 


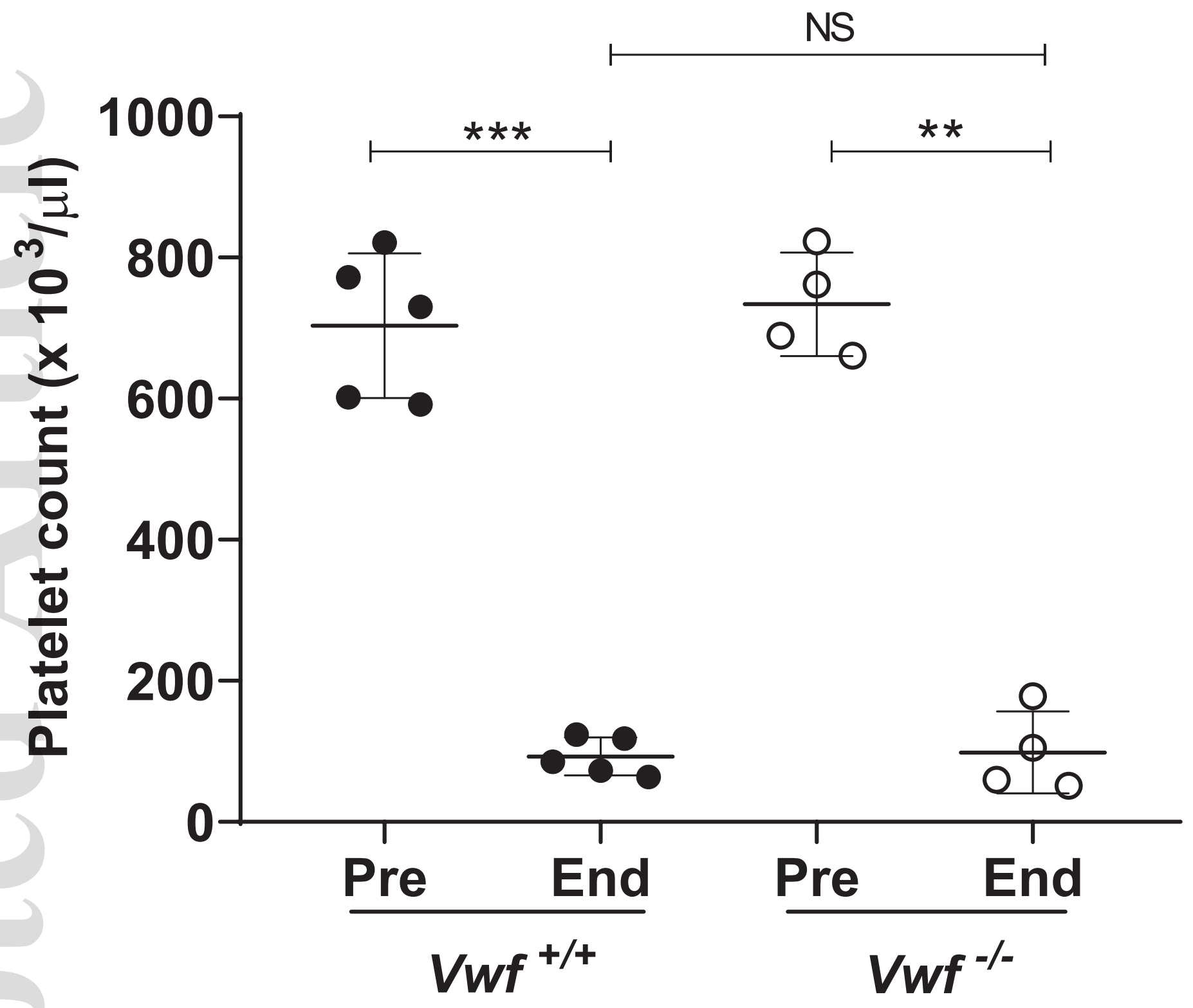

jth_14932_f3.eps 
A
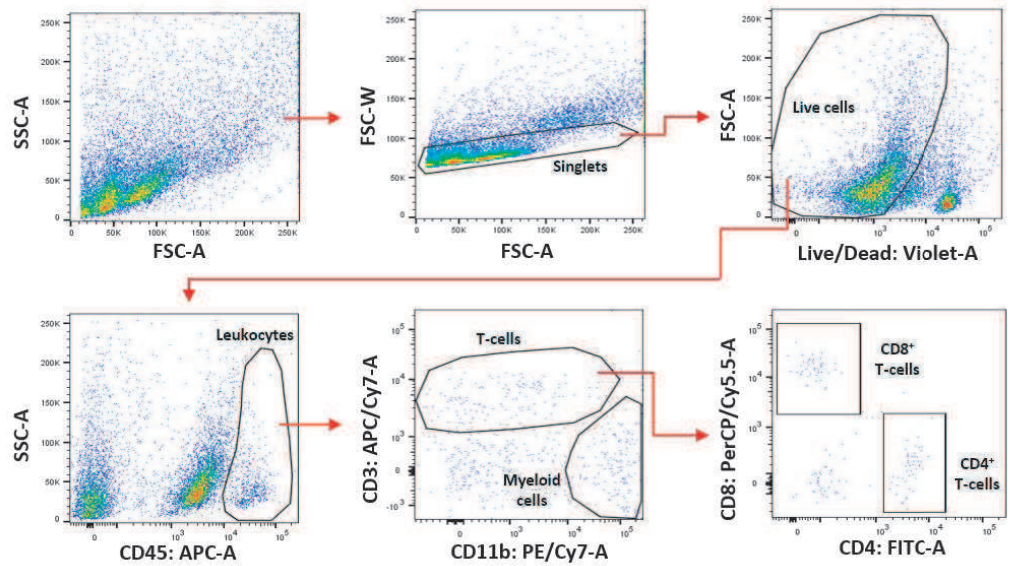

B
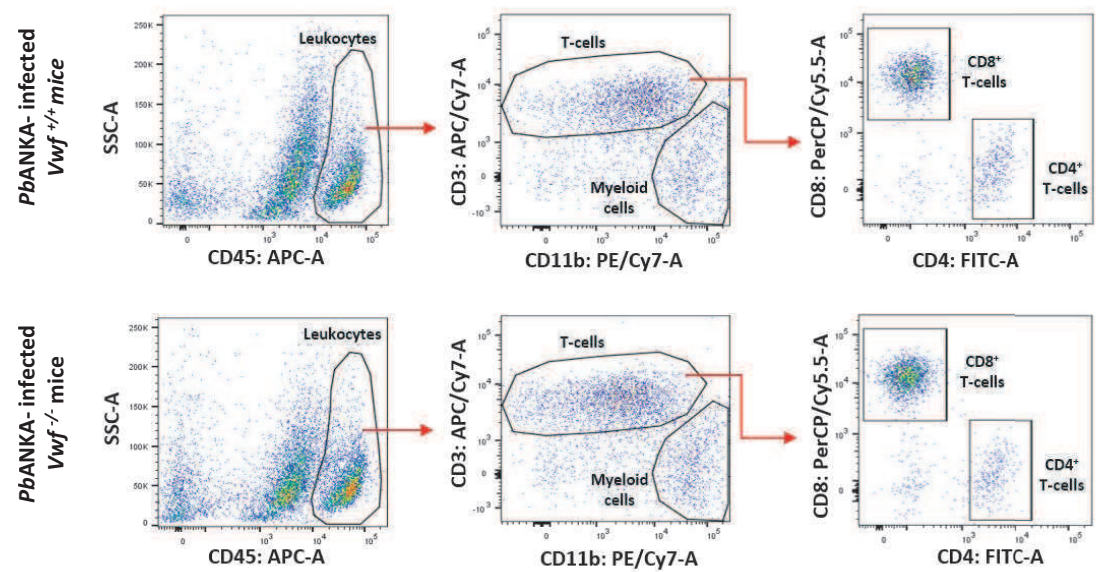

C
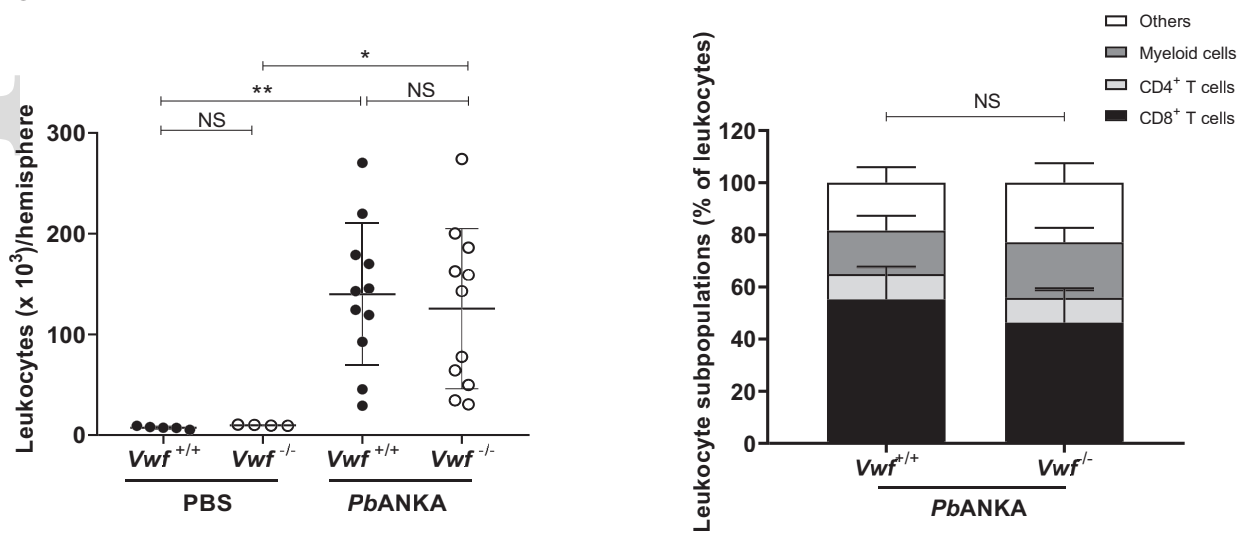
A

PBS

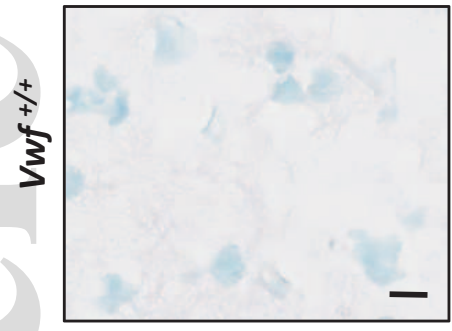

3

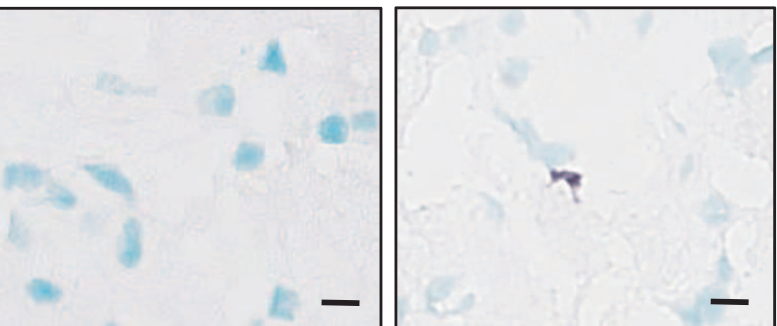

C

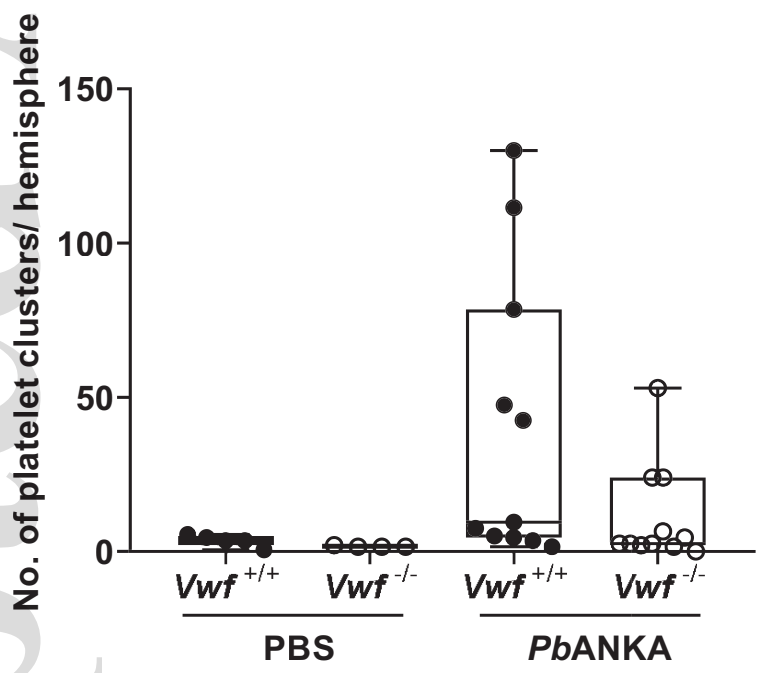

B

PBS
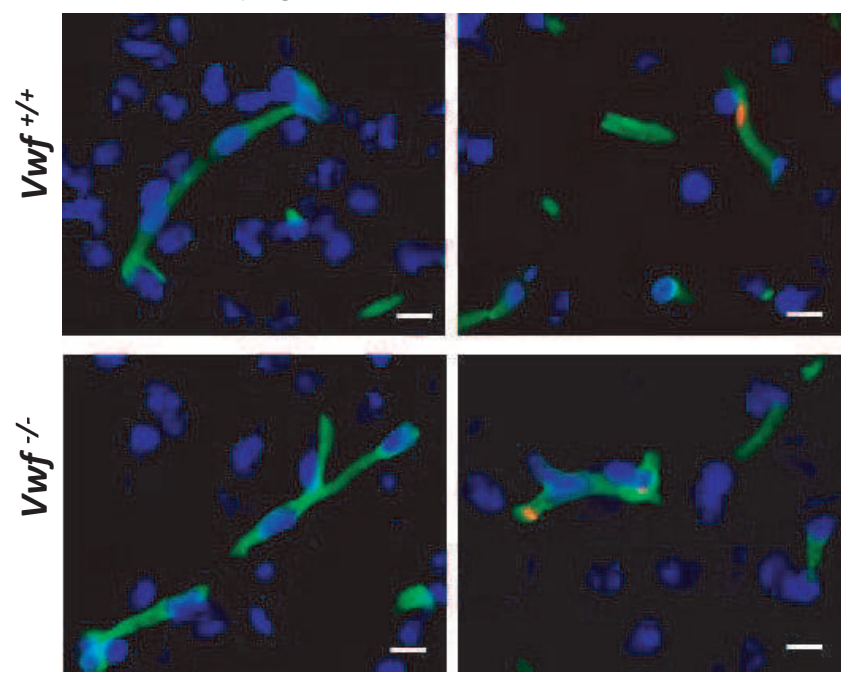

D

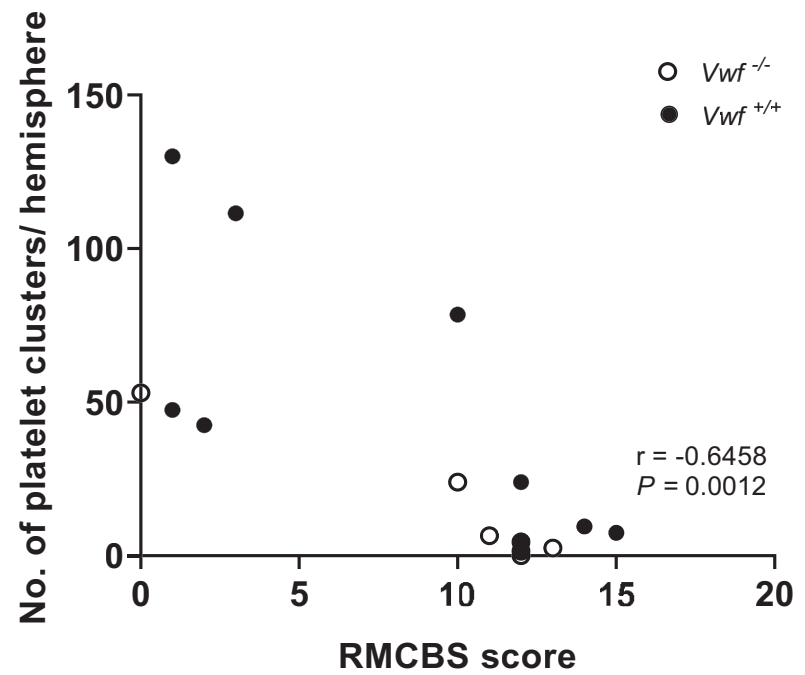

This article is protected by copyright. All rights reserved 